\title{
Ramification of crowdfunding on Bangladeshi entrepreneur's self-efficacy
}

\author{
Abu Shams Mohammad Mahmudul Hoque*, Zainudin Bin Awang, Habsah Muda, and \\ Fauzilah Salleh
}

Faculty of Economics and Management Sciences, Universiti Sultan Zainal Abidin (UniSZA), Terengganu, Malaysia

\begin{tabular}{l}
\hline C H R O N I C L E \\
\hline Article history: \\
Received March 1, 2018 \\
Received in revised format \\
March 112018 \\
Accepted April 252018 \\
Available online \\
April 25 2018 \\
\hline Keywords: \\
Crowdfunding \\
Entrepreneur Self-efficacy \\
Structural Equation Modeling \\
(SEM)
\end{tabular}
\begin{abstract}
A B S T R A C T
The novel funding sources turn out to be important for the Small and Medium Enterprises (SMEs) sector all over the world especially after 2007-2008 world financial crisis. Thus, to develop a new business idea and start-ups, SMEs need a sufficient amount of capital. However, after the financial crisis in 2008, SME sector faced the challenges of attracting new capital. Therefore, an innovative method of fundraising for SME was introduced as crowdfunding. Crowdfunding indicates financing a project or an idea via the internet owing the help from the many investors or donors of a society. Since there are limited works about the influence of Crowdfunding on Entrepreneur Self-efficacy (ESE), hence, to minimize the research gap and to achieve the objective of the study, we conduct a quantitative research among 190 entrepreneurs in Bangladesh using crowdfunding based on Social Cognitive theory. The data were analyzed using Structural Equation Modeling (SEM) in IBM-SPSS-Amos 25.0 and the stated hypotheses were tested. The study found a direct and positive effect of Crowdfunding on Entrepreneur's Self-efficacy $(\beta=0.924, \mathrm{P}=.001$ ). Overall, the result has landed support for crowdfunding, which indicates that it can influence on self-efficacy of entrepreneur. In order to determine the need of crowdfunding, we have explained and statistically demonstrated how crowdfunding can provide a supplementary channel where firms can gain finance and to create self-efficacy of entrepreneurs through exploiting the potential of internet.
\end{abstract}

\section{Introduction}

According to Silver et al. (2016), during the last epoch the funding to entrepreneurial ventures has been squabbled extensively by the academics and by policy-makers (Stanworth \& Gray, 1991; Bolton, 1971; Macmillan, 1931). Overall, most small and medium enterprises (SMEs) maintain recurrent complications in obtaining the financial resources that are lifeblood for development of their businesses. From the commencement of the 20th century, most of the governments in the world have attempted various approaches in upholding the quality and quantity of funding that are available to SMEs. Hence, the novel funding sources turn out to be more and more significant in the SME sector especially after 2007-2008 world financial crisis. Therefore, to develop a new business idea, and startups, SME needs a sufficient amount of capital. However, after the financial crisis in 2008, SME sector faced the challenges of attracting new capital. Due to that, an innovative method of fundraising for

* Corresponding author.

E-mail address: mhhoque1982@gmail.com (A.S.M.M. Hoque) 
SME was introduced as crowdfunding. Silver et al. (2016) and Ward and Ramachandran (2010) mentioned that, crowdfunding is financial activities for supporting projects with or without maximizing profit using Internet. According to Silver et al. (2016), crowdfunding can be accredited to the developing microfinance group and in some instances is correlated to this kind of funding. Silver et al. (2016); Eranti (2014); and Ordanini et al. (2011) revealed that crowdfunding has been specifically valuable for financing inimitable projects realized as challenging to get funding from conventional sources. Therefore, crowdfunding indicates financing a project or an idea via the internet owing the help from the many investors or donors of a society. Though computer based supportive work studies have initiated to deal with how this novel form of funding stimuluses entrepreneurial function, less is known about the influence of crowdfunding on entrepreneur's self-efficacy to succeed at a business task, which is affected by searching, planning, marshaling, and implementing.

\section{Literature Review}

Fund is boosted via online platforms using Web 2.0 technologies from the people living in different geographical areas and is known as crowdfunding, which is also a new funding practice (Bottiglia \& Pichler, 2016). Even though crowdfunding may seem to be a recent trend, but actually, it is not, as in 1876, the Statue of Liberty was funded via crowdfunding, with the citizens of France for the statue and the United States for the pedestal (Bottiglia \& Pichler, 2016; Best \& Neiss 2014). However, the current epidemic growth of crowdfunding is mostly due to 2007-2008 global financial crisis as well as to innovation of Web 2.0 technology. Beside of this, it is widely recognized that, bank credit has almost ceased later than the breakdown of the US bank Lehman Brothers mostly in Europe and North America and serious financial crisis arise in the year 2007-2008 (Bottiglia \& Pichler, 2016). Hence, financing for SMEs and individuals lessened dramatically and significantly during the crisis, which generating a space for crowdfunding as an unconventional system for raising money (Hagedorn \& Pinkwart, 2016; Bottiglia \& Pichler, 2016; Dapp, 2013). As a result, distinct types of crowdfunding alternatives has been developed over time.

\subsection{Crowdfunding}

Crowdfunding is a new method of funding based on internet in which individuals ask for assistances through dedicated crowdfunding websites for projects (Bottiglia \& Pichler, 2016). It is distinct from the definition of crowdfunding that there are three attributes which are indispensable for crowdfunding. They are: (1) there have to be a business project, which necessitates funding; (2) there have to be several investors and those investors want to assist to carry out of that project; and (3) the internet will connect investors and entrepreneurs (Bottiglia \& Pichler, 2016). Based on the works of Moritz and Block, (2016); Hagedorn and Pinkwart, (2016); Wardrop et al. (2015); Bellefl amme and Lambert (2014); Dix and Luzar, (2014); Wilson and Testoni, (2014); Pierrakis and Collins, (2013); Harrison and Mason (1992); De Buysere et al. (2012); and Hemer (2011) the dimensions of crowdfunding are donation, sponsoring, pre-selling, social-lending, and equity-crowdfunding. Donation indicates individuals will allocate money to a business project or an innovative idea to carry out of that business project or idea as well as not to anticipate whatsoever in conversion of that allocated fund. This is the conventional factor of crowdfunding exploited by non-profit organizations, including election campaigns and disaster-relief campaigns (Harrison \& Mason, 1992; Pierrakis \& Collins, 2013). In sponsoring the originator and the investor come to an agreement on some sort of recompense which boosts the reliability and social footing of the investor. Whereas, according to Wardrop et al. (2015); and Bellefl amme and Lambert (2014), pre-selling is the reimbursement which is the material verdict of buying an inimitable product before those not participating. According to De Buysere et al. (2012), all the way through social lending, the money is collected using online platforms for social projects only and not pay interest or principal. However, in the equity crowdfunding, the donors are offered a definite number of shares in an economic project. According to Moritz and Block (2016), it is the trickiest factor in the crowdfunding theme (Hagedorn \& Pinkwart, 2016; Dix \& Luzar 2014). Therefore, crowdfunding 
denotes to conditions in which individuals supply naturally small extents of money to the economic projects or innovative ideas either directly or via online platforms.

\subsection{Self-efficacy}

The changeable spirit of entrepreneurial function, distinct the design of a new enterprise (Shane, 2003), entails that entrepreneur's confidence in their own capabilities appropriately to take action (McMullen $\&$ Shepherd, 2006). According to Chen et al. (1998) entrepreneurial self-efficacy is entrepreneur's own capabilities to succeed at entrepreneurial tasks, influences performance positively as well as to set the goals of entrepreneur (Chen et. al., 1998). Self-efficacy can significantly stimulus performance, and entrepreneurial intentions. On the other hand, crowdfunding can significantly influence the entrepreneur's self-efficacy. Rauch and Frese (2007) mentioned that entrepreneurial self-efficacy for commencing a new business project is a vital issue in growing the probability of business start-up activity. Consequently, Chen et al. (1998) mentioned that limited financing negatively affects the selfefficacy of an entrepreneur as well as lack of self-efficacy is improbable to work at novel projects and believe in their aptitudes. Bandura's Social Cognitive Theory suggests that, self-efficacy can be established in four ways: experience of mastery, modeling, social persuasion, and physiological positions (Bandura, 1997). However, we comprehend how self-efficacy grows in face-to-face circumstances, but we recognize very little regarding how entrepreneurial self-efficacy grows in a computer-mediated practice, particularly via crowdfunding. Hence, the determination of this study is to explore the effect of crowdfunding on the self-efficacy of an entrepreneur as well as knowing that we can generate healthier socio-technical edges to strengthen entrepreneurs as they participate in their work. Hence the hypothesis of this study is:

H 1: Crowdfunding has significant effect on Self-efficacy of an entrepreneur.

\subsection{Conceptual Framework of the Study}

This study has been formulated based on Bandura's Social Cognitive Theory and the variables under investigation in this study are shown in the following schematic diagram.

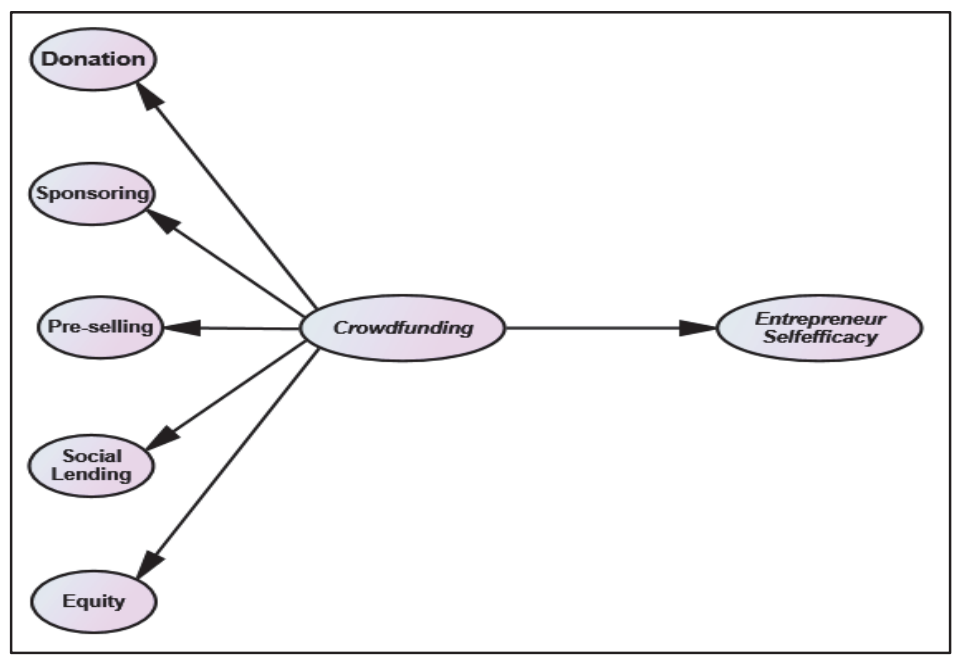

Fig. 1. Research Framework

\section{Research Methodology}

\subsection{Sample and Data Collection}

The purpose of this research is to investigate the effect of crowdfunding on ESE. The perceptions of owners of SMEs in Bangladesh were obtained through survey questionnaire to analyze the effect. In this regard, the survey questionnaire was circulating among the owners of SMEs in Bangladesh during 
their working hours. A total of 190 usable samples was collected. Grounded on gender, male constituted $57 \%$ while female represented $43 \%$ of the sample population.

\subsection{Instrumentation}

The ESE measurement was adopted with modifications from the work of Wilson et al. (2007) that has been divided into four phases namely searching, planning, marshaling, and implementing. The items of Crowdfunding were adopted with modifications from the work of Wingerden and Ryan (2011). Whereas items of entrepreneur's self-efficacy were adopted with modifications from the work of Hoque et al. (2017b). Items were assessed as subjective measure using a seven-point Likert scale.

\subsection{Method of Analysis}

Structural equation modelling is a technique of multivariate analysis, grown on the limitations in the conventional Ordinary Least Squares (OLS) and the analysis for latent constructs is no longer appropriate with traditional OLS (Hoque et al., 2017a; Hoque et al., 2017c; Hoque \& Awang, 2016a; Hoque \& Awang, 2016b; Kashif et al., 2016; Awang, 2015; 2014; Awang et al., 2015a). Thus, the researchers employed SEM to keep pace with the advancement in research methodology. The researchers used IBM-SPSS-AMOS software and converted their theoretical framework directly into the Amos Graphics for analysis. In SEM, the researcher validated the measurement model of a latent construct employing the Confirmatory Factor Analysis (CFA) procedure. Once validated, the researcher assembled the constructs into the structural model and execute the Structural Equation Modeling (SEM) procedure. Consequently, this study employed IBM-SEM-AMOS software package for analysis and testing the hypothesis.

\section{Results}

\subsection{Measurement Model}

Before doing path analysis in SEM, the study requires to confirm the measurement model validation of latent constructs for unidimensionality, validity, and reliability (Hoque et al., 2017a; Hoque et al., 2017d; Hoque \& Awang, 2016a; Awang 2014; 2015; Awang et al. 2015a). Unidimensionality is achieved when the factor loading of all sub-constructs and all of their items are positive with a minimum value of 0.6 (Hoque et al., 2017c; Hoque et al., 2017b; Hoque \& Awang, 2016a; Awang et al., 2015a; Hair et al., 2014; Awang 2014, 2015). Construct validity is achieved when the fitness indexes of the measurement model meet three model fit that is, Absolute fit, Incremental fit, and Parsimonious fit. Discriminant validity is achieved when all constructs are not highly correlated (Awang 2014; 2015; Awang et al., 2015a; Hair et al., 2014; Fornell \& Larcker, 1981). Convergent validity is achieved when the value of AVE meets the minimum value of 0.5 (Awang 2014; 2015; Awang et al., 2015a; Hair et al., 2014). The Construct reliability is achieved when the values of Composite reliability (CR) and AVE reach the minimum value of 0.6 and 0.5 respectively (Awang et al., 2017; Hoque et al., 2017a, Hoque et al., 2017c; Hoque \& Awang, 2016a; Awang et al., 2015a; Awang 2014; 2015; Hair et al., 2014; Fornell \& Larcker, 1981). The Internal Reliability among the items is achieved when the value of Cronbach Alpha reaches the minimum value of 0.7 (Awang et al., 2017; Fornell \& Larcker, 1981; Nunnally, 1978). All the Fitness Indexes (P-Value=.000; RMSEA=.073; IFI=.939; CFI=.938; $\mathrm{TLI}=.928 ; \mathrm{NFI}=.903 ; \mathrm{ChiSq} / \mathrm{df}=2.546)$ shown in Fig. 2 indicate the measurement model of the two latent constructs (i.e. CE and IP) have met the requirement as well as signifies a satisfactory fit to the data and result of all indexes was good. Hence, this study achieved the construct validity (Hoque \& Awang, 2016a; Awang et al., 2017; Awang 2015; Awang et al., 2015a). 


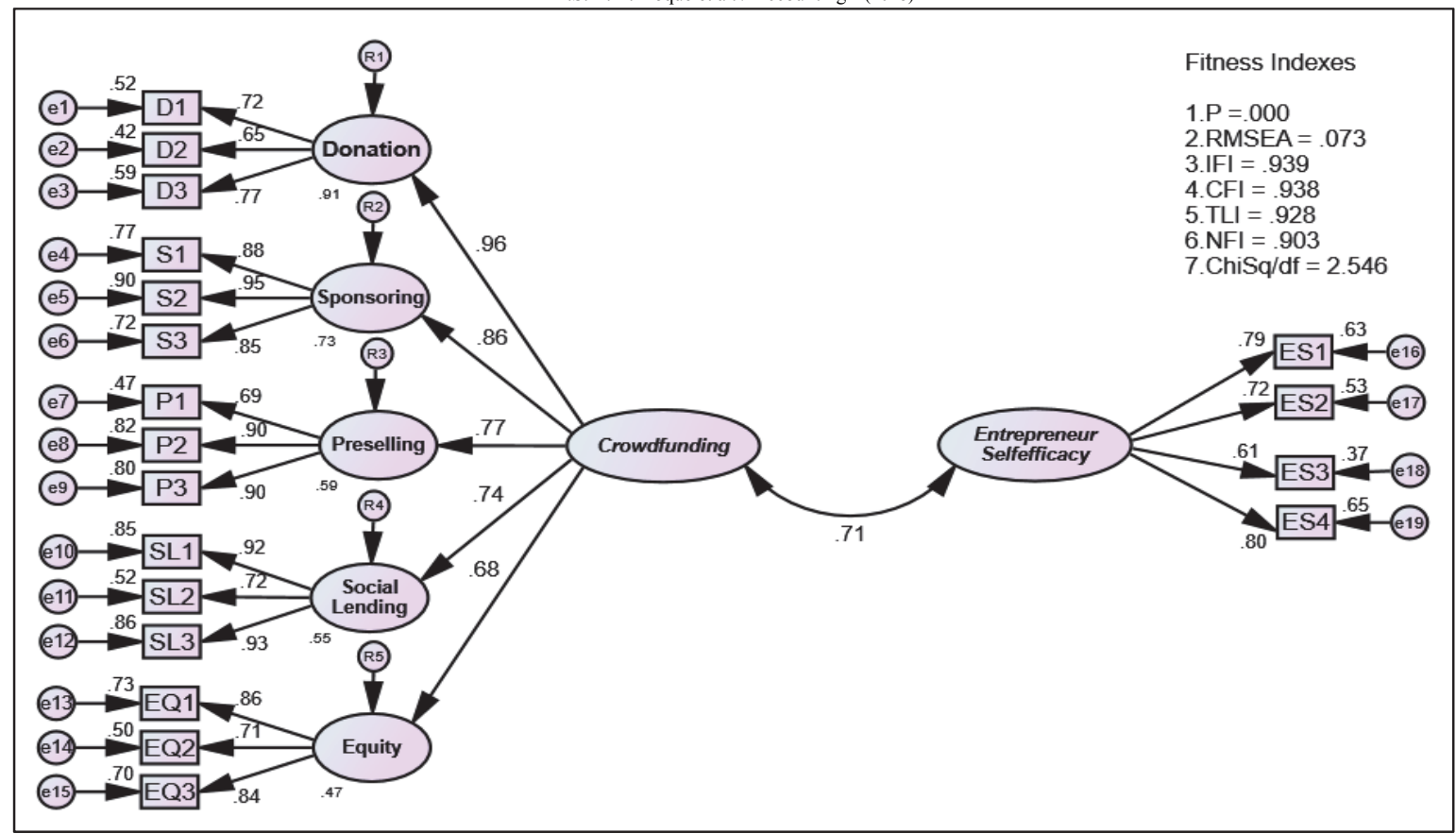

Fig. 2. The Pooled CFA Results and the Output Showed All Fitness Indexes Achieved

\section{Table 1}

Items Description, Internal Reliability, Composite Reliability and Convergent Validity

\begin{tabular}{|c|c|c|c|c|c|c|}
\hline Construct \& Dimensions & $\begin{array}{c}\text { Dimensions \& } \\
\text { Items }\end{array}$ & Item Factor Loading & $\mathrm{R}^{2}$ & $\begin{array}{c}\text { Cronbach's } \\
\text { Alpha }\end{array}$ & $\begin{array}{c}\text { Composite } \\
\text { Reliability }(\mathrm{CR}) \\
\text { (above } 0.6)\end{array}$ & $\begin{array}{c}\text { Average Variance } \\
\text { Extracted (AVE) } \\
\text { (above } 0.5 \text { ) }\end{array}$ \\
\hline \multirow{5}{*}{ Crowdfunding } & Donation & .96 & .91 & .750 & \multirow{5}{*}{.903} & \multirow{5}{*}{.653} \\
\hline & Sponsoring & .86 & .73 & .919 & & \\
\hline & Preselling & .77 & .59 & .864 & & \\
\hline & Social Lending & .74 & .55 & .889 & & \\
\hline & Equity & .68 & .47 & .840 & & \\
\hline \multirow{3}{*}{ Donation } & D1 & .72 & .52 & \multirow{3}{*}{.750} & \multirow{3}{*}{.757} & \multirow{3}{*}{.511} \\
\hline & D2 & .65 & .42 & & & \\
\hline & D3 & .77 & .59 & & & \\
\hline \multirow{3}{*}{ Sponsoring } & S1 & .88 & .7 & \multirow{3}{*}{.919} & \multirow{3}{*}{.923} & \multirow{3}{*}{.800} \\
\hline & S2 & .95 & .90 & & & \\
\hline & S3 & .85 & .72 & & & \\
\hline \multirow{3}{*}{ Preselling } & $\mathrm{P} 1$ & .69 & .47 & \multirow{3}{*}{.864} & \multirow{3}{*}{.873} & \multirow{3}{*}{.699} \\
\hline & P2 & .90 & .82 & & & \\
\hline & $\mathrm{P} 3$ & .90 & .80 & & & \\
\hline \multirow{3}{*}{ Social Lending } & SL1 & .92 & .85 & \multirow{3}{*}{.889} & \multirow{3}{*}{.896} & \multirow{3}{*}{.743} \\
\hline & SL2 & .72 & .52 & & & \\
\hline & SL3 & .93 & .86 & & & \\
\hline \multirow{3}{*}{ Equity } & EQ1 & .86 & .73 & \multirow{3}{*}{.840} & \multirow{3}{*}{.847} & \multirow{3}{*}{.650} \\
\hline & EQ2 & .71 & .50 & & & \\
\hline & EQ3 & .84 & .70 & & & \\
\hline \multirow{4}{*}{ Entrepreneur Self-efficacy } & ES1 & .79 & .63 & \multirow{4}{*}{.820} & \multirow{4}{*}{.822} & \multirow{4}{*}{.539} \\
\hline & ES2 & .72 & .53 & & & \\
\hline & ES3 & .61 & .37 & & & \\
\hline & ES4 & .80 & .65 & & & \\
\hline
\end{tabular}


The values of factor loading for every item of two constructs that comprise of both crowdfunding and entrepreneur self-efficacy together with the squared multiple correlations or $\mathrm{R}^{2}$, Cronbach Alpha, CR and AVE for every construct as shown in Table 1 which indicated both latent constructs (i.e. Crowdfunding and Entrepreneur Self-efficacy) have achieved Unidimensionality; Convergent Validity, Internal Reliability, and Construct Reliability. Moreover, the Discriminant validity is assessed through correlation and also through Discriminant Validity Index Summary. According to Awang $(2014 ; 2015)$ one of the criteria for Discriminant validity is the value of correlation between constructs must not exceed 0.85 (Awang et al., 2017; Hoque et al., 2017b; Hoque \& Awang, 2016a; Kline,1998). Table 2 which indicated the Discriminant Validity Index Summary as well as the diagonal value in Table 2 is square-root of AVE for the corresponding constructs, though further values are the correlation between constructs. The Discriminant validity of the constructs is achieved when the diagonal values of the Table 2 are greater than any values in their rows, and columns respectively (Awang et al., 2017; Hoque et al., 2017a, Hoque et al., 2017b; Hoque \& Awang, 2016a; Awang, 2015a; Fornell \& Larcker, 1981).

\section{Table 2}

Discriminant Validity Index Summary

\begin{tabular}{lcc}
\hline Construct & Crowdfunding & Entrepreneur Self-efficacy \\
\hline Crowdfunding & 0.808 & \\
Entrepreneur Self-efficacy & 0.710 & 0.734 \\
\hline
\end{tabular}

The correlation value of latent constructs Crowdfunding and Entrepreneur Self-efficacy is 0.710. As the square-root of AVE value in diagonal is greater than the value in row and column, this study accomplishes that the Discriminant validity is achieved for the model (Awang et al., 2017; Hoque et al., 2017a; Hoque et al., 2017b; Kashif et al., 2016; Hoque \& Awang, 2016a; Awang et al., 2015a; Fornell \& Larcker, 1981).

\subsection{The Structural Model}

As shown in Figure 3, the hypothesis $\mathrm{H}_{1}$ is supported. In $\mathrm{H}_{1}$, crowdfunding has a significant positive direct effect on entrepreneur self-efficacy of the firms $(\beta=0.924, \mathrm{P}=.001)$. The structural model explains $50.3 \%$ variance in entrepreneur self-efficacy.

\section{Table 3}

Squared Multiple Correlations $\left(\mathrm{R}^{2}\right)$

\begin{tabular}{lc}
\hline Variable & Estimate $\left(\mathrm{R}^{2}\right)$ \\
\hline Entrepreneur Self-efficacy & $\mathbf{0 . 5 0 3}$ \\
\hline
\end{tabular}

The above Table 3 indicates that the predictor of entrepreneur self-efficacy explains $50.3 \%$ of its variance. In other arguments, the error variance of entrepreneur self-efficacy is about $49.7 \%$ of the variance of entrepreneur self-efficacy.

Table 4

Standardized Regression Weights of CE on IP

\begin{tabular}{lccr}
\hline Variable & Path & Variable & Estimate \\
\hline $\begin{array}{l}\text { Entrepreneur Self- } \\
\text { efficacy }\end{array}$ & $\leftarrow$ & Crowdfunding & $\mathbf{0 . 7 1 0}$ \\
\hline
\end{tabular}

Table 4 base on Figure 3 showed that the influence of crowdfunding on entrepreneur self-efficacy was $71.0 \%$ while $29.0 \%$ does not influence entrepreneur self-efficacy. 
The unstandardized regression weight (i.e. shown in Fig. 4) indicated that the estimate of the beta coefficient that assess the effects of the crowdfunding construct on the entrepreneur self-efficacy construct.

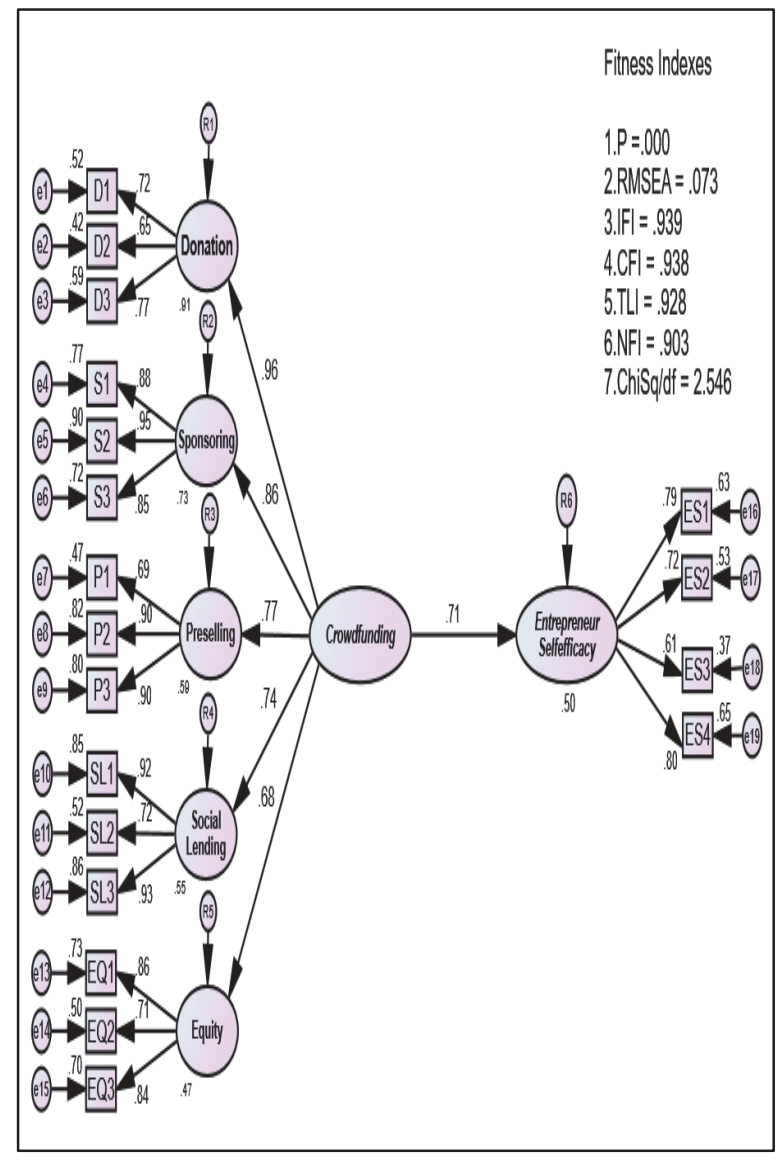

Fig. 3. Standardized Regression Path Coefficient

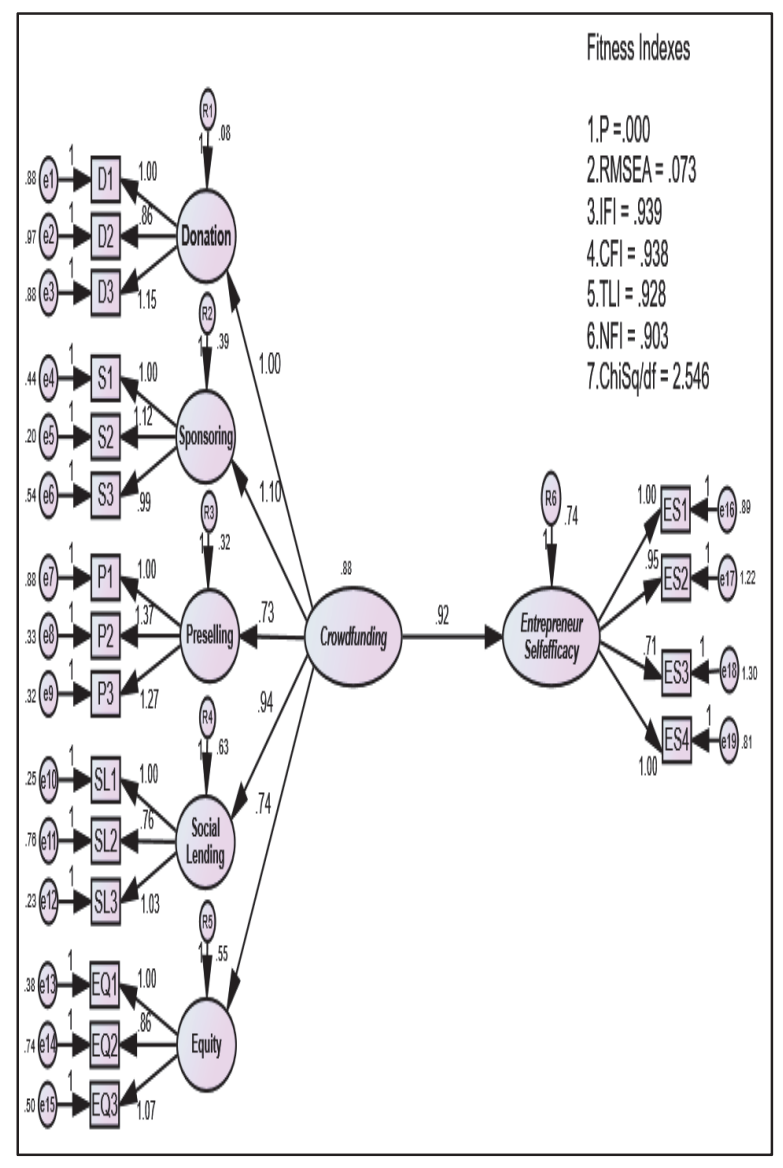

Fig. 4. Unstandardized Regression Path Coefficient

\section{Table 5}

Regression Weight for Path Estimate

\begin{tabular}{lccccccc}
\hline Variable & path & Variable & Estimate & S.E. & C.R. & P & Result \\
\hline $\begin{array}{l}\text { Entrepreneur } \\
\text { Self-efficacy }\end{array}$ & $\leftarrow$ & Crowdfunding & .924 & 0.100 & 9.197 & $* * *$ & Significant \\
\hline \multicolumn{1}{|l}{ Note: $* * * \mathrm{P}<0.01$} & & & & & & &
\end{tabular}

The hypothesis of this study was spelt out as: crowdfunding has a positive and significant effect on entrepreneur's self-efficacy. The result in Table 5 showed that the level of significance for regression weight indicates that the probability of getting a CR as large as 9.197 in absolute value is 0.001 . Whereas, the effect of crowdfunding on entrepreneur self-efficacy of the firms is highly significant. Consequently, the beta coefficient for the effect of crowdfunding on entrepreneur self-efficacy was .924 , which means that for each unit increase in crowdfunding, entrepreneur self-efficacy increased by .924. Therefore, the hypothesis was supported. Hence, this research suggested that there is a straightforward requirement and demand for Crowdfunding to increase entrepreneur self-efficacy for their business and to help in the national GDP of Bangladesh.

\section{Conclusion}

To sum up, we have explained and statistically proved how crowdfunding can deliver an extra support through which firms can completely utilize the potential of the internet as well as to create self-efficacy 
of entrepreneurs. However, crowdfunding is not always a suitable option for SMEs, as for crowdfunding the entrepreneurs have to unveil their business thought and strategy in public specially through online and which might be harmful for firms. Nevertheless, crowdfunding is crucial for better SME performance as it is enhancing entrepreneur's self-efficacy.

\section{References}

Awang, Z. (2014). A Handbook on SEM for Academicians and Practitioners: the step by step practical guides for the beginners. Bandar Baru Bangi: MPWS Rich Resources.

Awang, Z. (2015). SEM made simple: A Gentle Approach to Learning Structural Equation Modeling. Bandar Baru Bangi: MPWS Rich Resources.

Awang, Z., Ahmed, U., Hoque, A. S. M. M., Siddiqui, B. A., Dahri, A. S., \& Muda, H. (2017). The Mediating Role of Meaningful Work in the Relationship Between Career Growth Opportunities and Work Engagement, International Academic Confernce on Business and Economics (IACBE 2017), Faculty of Economics and Management Sciences (FESP), Universiti Sultan Zainal Abidin (UniSZA), October 07-08.

Awang, Z., Afthanorhan, A., Mohamad, M., \& Asri, M. A. M. (2015a). An evaluation of measurement model for medical tourism research: the confirmatory factor analysis approach. International Journal of Tourism Policy, 6(1), 29-45.

Bandura, A. (1997). Self-efficacy: The exercise of control. W. H. Freeman and Company.

Bellefl amme, P., \& Lambert. T. (2014). Crowdfunding: Some empirical fi ndings and microeconomic underpinnings. Forum Financier: Revue Bancaire et Financière, 4, 288-296.

Best, J., \& Neiss. S. (2014). Crowdfunding: A historical perspective. In Crowdfunding. A guide to raising capital on the Internet, ed. S. Dresner, 3-14. Hoboken: Wiley.

Bolton, J.E. (1971). Report of the committee of inquiry on small firms. Cmnd. 4811, London: HMSO.

Bottiglia, R., \& Pichler, F. (2016). Crowdfunding for SMEs. Springer, Macmillan Publishers Ltd. London.

Chen, C. C., Greene, P. G., \& Crick, A. (1998). Does entrepreneurial self-efficacy distinguish entrepreneurs from managers?. Journal of business venturing, 13(4), 295-316.

Dapp, T. F. (2013). Crowdfunding. An alternative source of funding with potential, Deutsche Bank Research, Banking and Technology Snapshot, March. www.dbresearch.com

De Buysere, K., Gajda, O., Kleverlaan,R., \& Marom, D. (2012). A framework for European crowdfunding. www.crowdfundingframework.eu

Dix, A., \& Luzar, C. (2014). Current market dynamics. In Crowdfunding. A guide to raising capital on the Internet, ed. S. Dresner, 47-80. Hoboken: Wiley

Fornell, C., \& Larcker, D. F. (1981). Structural equation models with unobservable variables and measurement error: Algebra and statistics. Journal of Marketing Research, 18(3), 382-388.

Hagedorn, A., \& Pinkwart. A. (2016). The financing process of equity-based crowdfunding: An empirical analysis. In Crowdfunding in Europe. State of the art in theory and practice, eds. D. Brüntje, and O. Gajda, 71-85. Berlin: Springer.

Hair, J.F., Hult, G.T., Ringle, C.M., \& Sarstedt, M. (2014). A Primer on Partial Least Squares Structural Equation Modelling. Thousand Oaks, California: SAGE Publications, Inc.

Harrison, R. T., and Mason, C. M. (1992). International perspectives on the supply of informal venture capital. Journal of Business Venturing, 7(6), 459-475.

Hemer, J. (2011). A snapshot on crowdfunding. Working papers firms and regions, No. R2/2011.

Hoque, A. S. M. M., \& Awang, Z. (2016a). The Sway of Entrepreneurial Marketing on Firm Performance: Case of Small and Medium Enterprises (SMEs) in Bangladesh, Terengganu International Business and Economics Conference (TiBEC-V), Terengganu, Universiti Teknologi Mara (UiTM), pp. 174-194. 
Hoque, A. S. M. M., \& Awang, Z. (2016b). Exploratory Factor Analysis of Entrepreneurial Marketing: Scale Development and Validation in the SME context of Bangladesh, International Social Sciences and Tourism Research Conference, Terengganu, UniSZA, pp. 20-22.

Hoque, A. S. M. M., Awang, Z., \& Salam, S. (2017a). The Effects of Relationship Marketing on Firm Performance: Small and Medium Enterprises (SMEs) in Bangladesh, 1st International Conference on Business and Management (ICBM-2017), BRAC Business School (BBS), BRAC University, Dhaka, Bangladesh, September 21-22.

Hoque, A. S. M. M., Awang, Z., \& Siddiqui, B. A. (2017b). Technopreneurial Intention among University Students of Business Courses in Malaysia: A Structural Equation Modeling. International Journal of Entrepreneurship and Small \& Medium Enterprise (IJESME), 4, 1-16.

Hoque, A. S. M. M., Awang, Z., Jusoff, K., Salleh, F., \& Muda, H. (2017c). Social Business Efficiency: Instrument Development and Validation Procedure Using Structural Equation Modeling. International Business Management, 11(1), 222-231.

Hoque, A. S. M. M., Gwadabe, U. M., \& Rahman, M. A. (2017d). Corporate Entrepreneurship Upshot on Innovation Performance: The Mediation of Employee Engagement. Journal of Humanities, Language, Culture and Business, 1(6), 54-67.

Kashif, M., Samsi, S. Z. M., Awang, Z., \& Mohamad, M. (2016). EXQ: measurement of healthcare experience quality in Malaysian settings: A contextualist perspective. International Journal of Pharmaceutical and Healthcare Marketing, 10(1), 27-47.

Kline, R. B. (1998). Principles and practice of structural equation modeling. New York: Guilford.

Macmillan Committee. (1931). Report of the committee on finance and industry. Cmnd. 3897, London: HMSO.

McMullen, J.S., \& Shepherd, D.A. (2006). Entrepreneurial action and the role of uncertainty in the theory of the entrepreneur. Academy of Management Review, 31(1), 132-152.

Moritz, A., and Block, J. (2016). Crowdfunding: A literature review and research directions. In Crowdfunding in Europe. State of the art in theory and practice, eds. D. Brüntje, and O. Gajda, 2553. Berlin: Springer.

Nunnally, J. C. (1978). Psychometric Theory (2 ${ }^{\text {nd }}$ ed.). New York: McGraw-Hill.

Pierrakis, Y., \& Collins, L. (2013). Crowdfunding: A new innovative model of providing funding to projects and businesses. SSRN Working Paper, May.

Rauch, A., \& Frese, M. (2007). Let's put the person back into entrepreneurship research: a metaanalysis on the relationship between business owners' personality traits, business creation, and success. European Journal of Work and Organizational Psychology, 16(4), 353-85.

Shane, S. (2003). A General Theory of Entrepreneurship: The Individual-Opportunity Nexus. Edward Elgar Publishing Limited, Northampton, MA.

Silver, L., Berggren, B., \& Fili, A. (2016). The role of crowdfunding in entrepreneurial ventures: an analysis of recent trends in Sweden. Investment Management and Financial Innovations, 13(1), 221229.

Stanworth, J., \& Gray, C. (eds) (1991). Bolton 20 Years on: The Small Firm in the 1990s. Paul Chapman: London.

Ward, C., \& Ramachandran, V. (2010). Crowdfunding the next hit: Micro-funding online experience goods. Proc. of NIPS, Workshop on Computational Social Science and the Wisdom of Crowds.

Wardrop, R., Zhang, B., Rau, R., \& Gray, M. (2015). Moving mainstream. The European alternative finance benchmarking report. Cambridge Centre for Alternative Finance and Ernst \& Young, February. www.jbs.cam.ac.uk

Wilson, F., Kickul, J., \& Marlino, D. (2007). Gender, entrepreneurial self-efficacy, and entrepreneurial career intentions: Implications for entrepreneurship education. Entrepreneurship Theory and Practice, 13, 387-406.

Wilson, K. E., \& Testoni, M. (2014). Improving the role of equity crowdfunding in Europe's capital markets. Bruegel Policy Contribution Issue 2014/09, August.

Wingerden, R. V., \& Ryan, J. (2011). Fight for Funds: An Exploratory Study into the Field of Crowdfunding. School of Economics and Management, Lund University. 


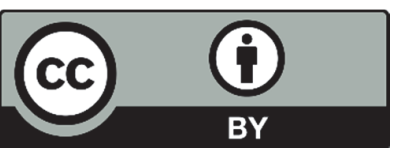

(C) 2018 by the authors; licensee Growing Science, Canada. This is an open access article distributed under the terms and conditions of the Creative Commons Attribution (CC-BY) license (http://creativecommons.org/licenses/by/4.0/). 